\title{
Termination of tonic immobility in chickens by auditory stimulation
}

\author{
DANIEL C. HATTON and RICHARD W. THOMPSON \\ Western Washington State College, Bellingham, Washington 28225
}

\begin{abstract}
The experiment investigated the effects of $60-, 70-, 80-$, or $90-\mathrm{dB}, 250-\mathrm{Hz}$ tones presented at $30-\mathrm{sec}$ intervals during tonic immobility (TI) on the duration of the response. Results indicated that all birds in the $90-\mathrm{dB}$ condition terminated TI with tone onset, $60 \%$ of the birds in the $80-\mathrm{dB}$ condition showed the maximal response $(1800 \mathrm{sec})$, and $30 \%$ terminated with tone onset. Two parallel responses were hypothesized to result from such stimulation: (1) fear, which increases TI duration and (2) a startle reaction, which terminates $\mathrm{TI}$.
\end{abstract}

Much of the current research on the effects of external stimuli on animal hypnosis or tonic immobility (TI) has been directed at testing the hypothesis that TI is the result of fear. For example, Gallup, Nash, Potter, and Donegan (1970) have shown that stimulation by electric shock or high intensity sounds prior to TI induction will prolong the duration of the response. However, little attention has been directed to the effects of stimulation during the response; will such stimuli lead to termination or will they increase the duration of the response? Ratner (1967), in reviewing the literature on TI pointed out that "the general consensus of reports is that any of a variety of stimuli such as loud noises, sudden visual presentations, or electric shock may lead to termination, particularly if the stimulation is intense and the onset is abrupt ([p. 566].' However, "one of the typical characteristics of hypnotic reactions is that animals are unresponsive during immobility. Thus, termination of the response to stimulation may be an index to the fact that the reaction has ceased [p. 566]."

Kirk (1966), working with frogs, noted that electric shock delivered during TI may have an arousing effect, but that the animal may not be able to initiate the movements necessary to attain the upright position. Draper and Klemm (1967) have also shown that heart rate conditioning occurs as rapidly for rabbits in TI as for those conditioned in the normal state indicating little or no apparent change in sensitivity to stimulation. However, Klemm (1971) has also indicated that very weak stimuli may disrupt TI in the rabbit. The intensity of the stimulus presented during TI may be important in determining whether TI is decreased, not changed, or increased in duration. The present experiment investigated the effects of various intensities of auditory stimulation presented during TI on the duration of TI.

This paper is based on a Master's thesis submitted to the Graduate School, Western Washington State College by Daniel C. Hatton.

Daniel C. Hatton is now at the University of Florida.

Requests for reprints should be sent to Richard W. Thompson, Department of Psychology, Western Washington State College, Bellingham, Washington 98225.

\section{METHOD}

\section{Subjects}

The subjects were $50 \mathrm{H} \& \mathrm{~N}$ White Leghorn cockerel chicks obtained from a local hatchery at approximately 1 day of age. The birds were housed in a group in a commercial brooder with thermostatically controlled temperature of $35^{\circ} \mathrm{C}$. Water and food $\downarrow$ were available at all times prior to testing. A 12 -h dark-light photoperiod was provided by artificial light.

\section{Apparatus}

Testing was performed in a $1.85 \times 2.00 \times 1.80 \mathrm{~m}$ sound deadened chamber manufactured by Suttle Equipment Corporation. Tonic immobility was initiated in a $28 \mathrm{~cm}$ square $\times 12 \mathrm{~cm}$ deep plywood induction box. A $15-\mathrm{W}$ bulb, mounted $3 \mathrm{~cm}$ behind a translucent plastic panel at either end of the box, provided lighting for the inside of the induction box. The front of the box was covered with a piece of black cheesecloth, which permitted observation of the subject without the subject seeing outside the box.

The induction box rested on a table inside the darkened sound deadened chamber. A $30-\mathrm{cm} 8-\mathrm{ohm}$ speaker, resting on a $7.5-\mathrm{cm}$ thick foam pad to reduce vibration of the table, was positioned $5 \mathrm{~cm}$ behind the induction box. The speaker was driven by a Hewlet-Packard audio oscillator amplified by a Knight Model KN 15 amplifier. The oscillator and amplifier generated a $250-\mathrm{Hz}$ tone at $60,70,80$, or $90 \mathrm{~dB}$. Background noise was $30 \mathrm{~dB}$. All sound pressure levels were determined by a General Radio decibel meter. Electronic timing and relay equipment permitted presentation of a 2 -sec tone every $30 \mathrm{sec}$.

A shock apparatus, painted flat black, consisted of $62-\mathrm{cm}$ wide, $30-\mathrm{cm}$ high and $10-\mathrm{cm}$ wide plywood box with a grid floor. Shock was provided by a C. J. Applegate Model 250 shock stimulator. The 1.0-mA, 3-sec shock was timed by electronic timers. The shock apparatus was located 1-m outside the test chamber.

\section{Procedure}

At 10 days of age the chicks were assigned to five groups of 10 birds each. One group received no auditory stimulation during TI, the other four groups received 60-, 70-, 80-, and $90-\mathrm{dB}$ tones of 2-sec duration every $30 \mathrm{sec}$ after the induction of Ti until the response terminated or $1800 \mathrm{sec}$ elapsed, whichever occurred first.

To assure a high level of TI, each bird was placed in the shock box and 30 -sec later received a 3 -sec $1.0-\mathrm{mA}$ shock. The bird was then removed from the shock appartus and immediately taken to the test chamber. The subjects was placed inside the induction box and held upright for $15 \mathrm{sec}$, rapidly turned and held on its side for $15 \mathrm{sec}$; and then gently released. Tonic immobility was 
timed from release to spontaneous righting occurred or $1800 \mathrm{sec}$ had elapsed. For the stimulated groups the first stimulus was presented $30 \mathrm{sec}$ after the initiation of TI and every $30 \mathrm{sec}$ thereafter to the end of the trial. The nonstimulated group was treated in an identical fashion except no auditory stimulation was presented. The birds were observed through a window from outside the test chamber.

\section{RESULTS}

Mean duration of TI for the five groups are presented in Figure 1. The differences seen in the figure were significantly reliable as indicated by a Kruskal-Wallis one way analysis $(H=21$, df $=4, p<.001)$. Subsequent analysis by Mann-Whitney U-tests indicated that the 90-dB group had a significantly shorter duration of TI than all other groups and the 70-dB had a significantly longer duration of TI than the $60-\mathrm{dB}$ group (all ps $<.002$, two-tailed).

Inspection of the individual data for each group indicated that all birds in the $90-\mathrm{dB}$ condition terminated TI with the onset of stimulation. Six of the 10 birds in the 80-dB condition showed the maximum 1800 -sec duration of $\mathrm{Ti}$, and three of the four remaining birds terminated TI with the onset of the stimulus. In the remaining groups, four birds in the 70-dB group, one in the 60-dB conditioned, and two in the no-tone conditioned, showed the maximum TI response. None of the birds in the $60-$ or $70-\mathrm{dB}$ condition terminated TI with the onset of the stimulus. A chi square test of the four stimulated groups of the number of animals showing the maximum possible response yielded a significant difference among conditions $\left(\chi^{2}=11.41\right.$, df $=3, \mathrm{p}<.01$ ).

\section{DISCUSSION}

As is obvious from Figure 1, the duration of TI is not a simple function of the intensity of stimulation during the response. The data of the $80-\mathrm{dB}$ condition is particularly interesting, six of the birds showing the maximal response and three terminating with the onset of stimulation as did all the birds in the $90-\mathrm{dB}$ condition. This suggests there may be two distinct effects of auditory stimulation on the duration of TI.

First, it would appear that auditory stimulation, if intense enough, can prolong the duration of TI, probably by increasing the level of fear elicited (Gallup, Nash, Potter, \& Donegan, 1970). The increasing number of animals showing the maximal response in the other groups as the intensity of the stimulation increased is supportive of this interpretation. Second, the sudden onset of the auditory stimulus may elicit a startle reaction which effectively terminates TI. That three of the four animals in the

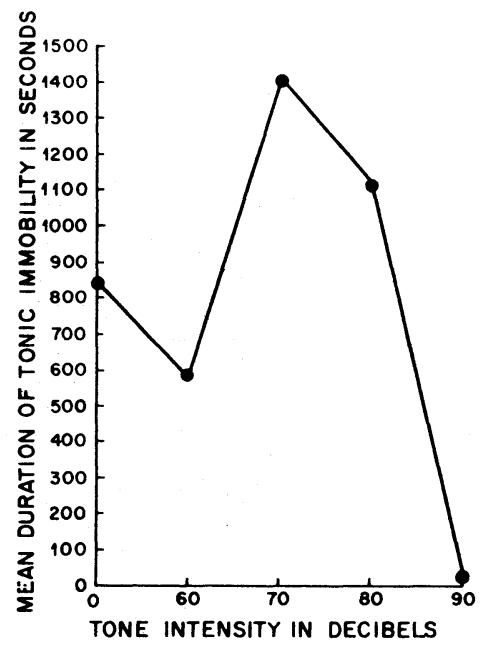

Figure 1. Mean duration of tonic immobility in seconds for each group.

80- $\mathrm{dB}$ condition not showing the maximal duration of TI and all of the 90-dB condition animals terminated with the onset of stimulation is consistent with this interpretation. In the 60- and 70-dB conditions, the stimulation was not intense enough to generate additional fear to produce increased TI nor was the startle reactions sufficient to cause termination of the response.

Thus, during TI as auditory stimulation increases in intensity, it causes increases in fear in the animal and produces longer durations of TI. At the same time as the intensity of the auditory stimuli increases, it also evokes startle reactions of increasing magnitudes. At some point the startle reaction is great enough to cause termination of the response.

\section{REFERENCES}

Draper, D. C., \& Klemm, W. R. Behavioral response associated with animal hypnosis. The Psychological Record, 1967, 17, 13-21.

Gallup, G. G., Jr., Nash, R. F., Potter, R. J., \& Donegan, N. H. Effect of varying conditions of fearm on immobility reaction in domestic chickens (Gallus, gallus). Journal of Comparative and Physiological Psychology, 1970, 73, 442-445.

Kirk, W. E. The effect of shock on duration of an immobility response of frogs. Paper presented at the Psi Chi paper session, Midwestern Psychological Association, Chicago, 1966.

Klemm, W. R. Neurophysiologic studies of the immobility reflex ("animal hypnosis"). In S. Ehrenpreis and O. S. Solnitzky (Eds.), Neurosciences Research. Vol. 4, New York: Academic Press, 1971, Pp. 165-212.

Ratner, S. Comparative aspects of hypnosis. In Gordon, J. E. (Ed.), Handbook of clinical and experimental hypnosis. New York: Macmillan, 1967, Pp. 550-586.

(Received for publication September 27, 1974.) 